Mappemonde

Revue trimestrielle sur l'image géographique et les formes du territoire

$126 \mid 2019$

Varia

\title{
Prix de thèse 2019
}

Clarisse Didelon-Loiseau et Laurent Jégou

\section{OpenEdition}

\section{Journals}

Édition électronique

URL : http://journals.openedition.org/mappemonde/1214

DOI : 10.4000/mappemonde.1214

ISSN : 1769-7298

Éditeur

UMR ESPACE

\section{Référence électronique}

Clarisse Didelon-Loiseau et Laurent Jégou, «Prix de thèse 2019 », Mappemonde [En ligne], 126 | 2019,

mis en ligne le 01 avril 2019, consulté le 15 septembre 2020. URL : http://journals.openedition.org/ mappemonde/1214

Ce document a été généré automatiquement le 15 septembre 2020.

\section{c) (i) (2)}

La revue Mappemonde est mise à disposition selon les termes de la Licence Creative Commons Attribution - Pas d'Utilisation Commerciale - Partage dans les Mêmes Conditions 4.0 International. 


\title{
Prix de thèse 2019
}

\author{
Clarisse Didelon-Loiseau et Laurent Jégou
}

1 Après délibération lors de la réunion du comité de rédaction de la revue du 20 septembre 2019 à l'Institut de Géographie, le Prix de Thèse Mappemonde 2019 a été décerné.

2 Ce prix récompense, rappelons-le, «une thèse de doctorat de qualité, où l'image géographique (prise au sens large: cartes, photographies, modèles, croquis et cartogrammes, représentation de données satellitaires, SIG, animations) aura été mobilisée de manière particulièrement pertinente dans le raisonnement scientifique ».

3 Quatre travaux étaient en compétition sur les 6 thèses sélectionnées par la section 23 du CNU lors de sa session de qualification 2019, ceux de :

- Morgane Flegeau, Julie Gravier, David Lagarde et Quentin Morcrette

\section{Le prix de thèse 2019 de Mappemonde est attribué à :}

- David Lagarde (Université Toulouse 2) pour son travail intitulé Sur les routes de l'exil syrien. Récits de vie et parcours migratoires des réfugiés de Deir Mqaren

5 Le comité de rédaction félicite le lauréat et souligne la remarquable qualité iconographique et cartographique des travaux reçus. Mappemonde remercie vivement l'ensemble des participants à ce concours, qui témoigne de la vitalité de la jeune recherche en France, ainsi que la section 23 du CNU qui contribue à la sélection des thèses candidates au Prix.

6 L'association Reclus dote le prix de 500 euros, somme qui sera remise au lauréat qui viendra présenter ses travaux lors de la réunion du comité de rédaction de janvier 2020.

7 Le lecteur trouvera dans un prochain numéro, dans la rubrique «Images », la présentation des travaux de thèse de l'ensemble des candidats ayant participé au Prix. 
INDEX

Mots-clés : Prix de thèse 